\title{
The devil is in the third year: a longitudinal study of erosion of empathy in medical school.
}

\author{
Mohammadreza Hojat \\ Thomas Jefferson University \\ Michael J. Vergare \\ Thomas Jefferson University \\ Kaye Maxwell \\ Thomas Jefferson University \\ George Brainard \\ Thomas Jefferson University
} Sollow this and additional works at: https://jdc.jefferson.edu/phbfp

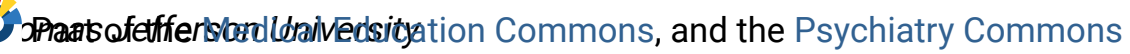
Let us know how access to this document benefits you

See next page for additional authors

\section{Recommended Citation}

Hojat, Mohammadreza; Vergare, Michael J.; Maxwell, Kaye; Brainard, George; Herrine, Steven K.; Isenberg, Gerald A.; Veloski, John; and Gonnella, Joseph S., "The devil is in the third year: a longitudinal study of erosion of empathy in medical school." (2009). Department of Psychiatry and Human Behavior Faculty Papers. Paper 37.

https://jdc.jefferson.edu/phbfp/37

This Article is brought to you for free and open access by the Jefferson Digital Commons. The Jefferson Digital Commons is a service of Thomas Jefferson University's Center for Teaching and Learning (CTL). The Commons is a showcase for Jefferson books and journals, peer-reviewed scholarly publications, unique historical collections from the University archives, and teaching tools. The Jefferson Digital Commons allows researchers and interested readers anywhere in the world to learn about and keep up to date with Jefferson scholarship. This article has been accepted for inclusion in Department of Psychiatry and Human Behavior Faculty Papers by an authorized administrator of the Jefferson Digital Commons. For more information, please contact: JeffersonDigitalCommons@jefferson.edu. 


\section{Authors}

Mohammadreza Hojat, Michael J. Vergare, Kaye Maxwell, George Brainard, Steven K. Herrine, Gerald A. Isenberg, John Veloski, and Joseph S. Gonnella 


\title{
The Devil is in the Third Year: A Longitudinal Study of Erosion of Empathy in Medical School
}

\author{
Hojat, Mohammadreza PhD; Vergare, Michael J. MD; Maxwell, Kaye; Brainard, George \\ PhD; Herrine, Steven K. MD; Isenberg, Gerald A. MD; Veloski, Jon MS; Gonnella, Joseph \\ S. MD
}

Dr. Hojat is research professor of psychiatry and human behavior, Department of Psychiatry and Human Behavior, and director, Jefferson Longitudinal Study of Medical Education, Center for Research in Medical Education and Health Care, Jefferson Medical College, Philadelphia, Pennsylvania.

Dr. Vergare is senior vice president for academic affairs and The Daniel Lieberman Professor and Chairman, Department of Psychiatry and Human Behavior, Jefferson Medical College of Thomas Jefferson University, Philadelphia, Pennsylvania.

Ms. Maxwell is manager of testing services, Center for Research in Medical Education and Health Care, Jefferson Medical College, Philadelphia, Pennsylvania.

Dr. Brainard is professor of neurology and director, Light Research Program, Jefferson Medical College, Philadelphia, Pennsylvania.

Dr. Herrine is professor of medicine, Division of Gastroenterology and Hepatology, and assistant dean for academic affairs, Jefferson Medical College, Philadelphia, Pennsylvania.

Dr. Isenberg is associate professor of surgery and director of undergraduate education, Department of Surgery, Program Director for Colorectal Residency, Jefferson Medical College, Philadelphia, Pennsylvania.

Mr. Veloski is director, Medical Education Division, Center for Research in Medical Education and Health Care, Jefferson Medical College, Philadelphia, Pennsylvania.

Dr. Gonnella is dean emeritus, Distinguished Professor of Medicine, and founder and director, Center for Research in Medical Education and Health Care, Jefferson Medical College, Philadelphia, Pennsylvania.

\begin{abstract}
Purpose: This longitudinal study was designed to examine changes in medical students' empathy during medical school and to determine when the most significant changes occur.
\end{abstract}


Method: Four hundred fifty-six students who entered Jefferson Medical College in 2002 ( $\mathrm{n}=$ 227) and $2004(\mathrm{n}=229)$ completed the Jefferson Scale of Physician Empathy at five different times: at entry into medical school on orientation day and subsequently at the end of each academic year. Statistical analyses were performed for the entire cohort, as well as for the "matched" cohort (participants who identified themselves at all five test administrations) and the "unmatched" cohort (participants who did not identify themselves in all five test administrations).

Results: Statistical analyses showed that empathy scores did not change significantly during the first two years of medical school. However, a significant decline in empathy scores was observed at the end of the third year which persisted until graduation. Findings were similar for the matched cohort $(n=121)$ and for the rest of the sample (unmatched cohort, $n=335$ ). Patterns of decline in empathy scores were similar for men and women and across specialties.

Conclusions: It is concluded that a significant decline in empathy occurs during the third year of medical school. It is ironic that the erosion of empathy occurs during a time when the curriculum is shifting toward patient-care activities; this is when empathy is most essential. Implications for retaining and enhancing empathy are discussed.

Medicine at its core is a human service profession. Cultivating humanistic values in general and enhancing interpersonal skills and empathy in particular are of paramount importance in any human service endeavor. Consistent with this notion, the Medical School Objectives Project of the Association of American Medical Colleges 1 includes enrichment of interpersonal skills and empathy among the educational objectives of undergraduate medical education. In a position paper, the American Board of Internal Medicine 2 recommended that humanistic values and empathy should be cultivated and assessed as an essential educational activity in graduate medical education.

Despite the consensus of professional organizations and medical education leaders on the importance of empathy in medical education and the practice of medicine, empirical research on empathy, including its development, and erosion is scarce. Consequently, 
sufficient attention has not been directed toward the enhancement of empathic skills for physicians-in-training.

Empirical research on empathy among medical students and physicians has been hampered not only by a conceptual confusion but also by the lack of a sound instrument to measure empathy specifically in the context of medical education and patient care. Without a valid measurement of empathy that is content-specific to patient care, it is not feasible to determine what factors lead to its enhancement or degradation among physicians-intraining.

\section{What Is Empathy?}

Empathy is an ambiguous concept. Despite a lack of consensus about its definition, there are various descriptions or characterizations of the term in the literature. $3^{\text {(pp 3-15) }}$ Because of this conceptual ambiguity, empathy has been described as a notion that is difficult to define and hard to measure. 4

Generally, some researchers have described empathy as a cognitive attribute,5,6 which means it predominantly involves understanding another person's concerns. Others have described empathy as an affective or emotional characteristic,7,8 which implies that it primarily involves feeling another person's pain and suffering. Yet, there is a third group that views empathy as both affective and cognitive.9,10

A clear conceptualization of empathy is critically important because conceptualization not only can serve as a guideline for an operational definition of the term but also can provide a framework for the development of a content-specific instrument for measuring empathy in the context of medical education and patient care. Also, strategies to enhance empathy can be more appropriately developed on the basis of a clear definition of the concept.

To clarify the conceptual ambiguity associated with empathy, based on an extensive review of relevant literature,3,11 we defined empathy in the context of medical education and patient care as a predominantly cognitive (as opposed to affective or emotional) attribute 
that involves an understanding (as opposed to feeling) of patients' experiences, concerns, and perspectives combined with a capacity to communicate this understanding. An intention to help by preventing and alleviating pain and suffering is an additional feature of empathy in the context of patient care.

The key terms in this definition are italicized for two reasons: (1) to underscore their importance in the construct of empathy in the context of medical education and patient care, and (2) to make a distinction between empathy and sympathy, which have often been used interchangeably.

\section{Empathy versus sympathy}

Sympathy, as opposed to empathy, is predominantly an affective or emotional attribute that involves intense feelings of a patient's pain and suffering. Despite the differences in conceptualization, the two notions are not entirely independent. One study reported a moderate correlation of 0.49 between measures of the two concepts, which can be translated into approximately a $25 \%$ overlap between the two. 12

The interchangeable use of these two concepts may not cause a problem in the context of social psychology, but it is important to separate the two in the context of patient care. In social psychology, both empathy and sympathy can lead to a similar outcome (e.g., prosocial behavior), albeit for different behavioral motivations. For example, a prosocial behavior that is induced by empathic understanding is more likely to be elicited by a sense of altruism. A prosocial behavior that is prompted by sympathetic feelings, however, is more likely to be triggered by egoistic motivation to reduce personal distress. 3

In the context of medical education and patient care, however, we must make a distinction between the two constructs because, in this context, they lead to different clinical behavior and patient outcomes.13 An empathic physician would be more concerned about understanding of the kind and quality of patients' experiences, whereas a sympathetic physician would be more concerned about feeling the degree and intensity (quantity) of patients' experiences. 3 Because of its cognitive nature, empathy in excess is always 
beneficial in patient-physician relationships. In contrast, because of its affective nature, an overabundance of sympathy can be detrimental in patient-physician relationships and can impede the neutrality that is necessary in clinical decision making, thus negatively influencing a physician's performance. Cognitively defined empathy always leads to personal growth, career satisfaction, and optimal clinical outcomes, whereas affectively defined sympathy can lead to career burnout, compassion fatigue, exhaustion, and vicarious traumatization. 14

Indeed, it can be assumed that the relationship between empathy and positive outcomes is linear, meaning that the outcomes progressively become better as a function of an increase in empathy. In contrast, it can be assumed that the relationship between sympathy and clinical outcomes is like an inverted $U$ shape (similar to that between anxiety and performance), meaning that sympathy to a limited extent can be beneficial, but excessive sympathy can be detrimental.

Another important implication for making a distinction between empathy and sympathy in medical education is the fact that affect and emotion (the prominent ingredients of sympathy) are less amenable to change, whereas cognition and understanding (the prominent ingredients of empathy) can be substantially enhanced by education. This implies that empathy can be taught, but sympathy is not easily amenable to change through education. Specific features of empathy and sympathy are summarized in Table 1. More detailed descriptions of those features are given elsewhere. $3^{\text {(pp 7-15,79-85) }}$

\section{Measurement}

To the best of our knowledge, before the development of the Jefferson Scale of Physician Empathy (JSPE), no psychometrically sound research instrument was available to measure empathy specifically among medical students, residents, and physicians. A few research tools exist for measuring empathy in the general population, $3^{\text {(pp 63-74) }}$ but none is contentspecific to medical education and relevant to patient care. Although they are not contentspecific, three empathy-measurement instruments have been frequently used in medical 
education research. The Interpersonal Reactivity Index (IRI) was developed by Davis 9 and includes 28 items tapping both cognitive and emotional empathy. The IRI contains four scales: perspective taking, empathic concern, fantasy, and personal distress. A typical item (from the perspective taking scale) is, "I sometimes try to understand my friends better by imagining how things look from their perspective."

Another research tool is the Empathy Scale developed by Hogan 15 which includes 64 items. A typical item is, "I have seen some things so sad that I almost felt like crying." The third research tool is the Emotional Empathy scale developed by Mehrabian and Epstein 16 which includes 33 items intended to measure "emotional empathy." A typical item is, "It makes me sad to see a lonely stranger in a group." Mehrabian introduced a new 30-item instrument, the Balanced Emotional Empathy Scale (BEES),17 to measure vicarious emotional empathy. A sample item is, "Unhappy movie endings haunt me for hours afterward." As indicated before, and reflected in the sample items, none of the aforementioned instruments feature content specific to medical education and patient care. With the exception of the BEES, extensive psychometric data have been published for the other three instruments. $3^{(\mathrm{pp} 66-69,72-73)}$

\section{The JSPE}

Several years ago, a group of medical education researchers at Jefferson Medical College recognized a need for an instrument to measure empathy in the context of medical education and patient care. In response to this need, and on the basis of the abovementioned, cognitively defined empathy and a comprehensive review of the literature, they developed the JSPE. Step-by-step procedures in the development of the JSPE and data in support of its validity and reliability are reported elsewhere. $3^{(\mathrm{pp} \text { 87-115) }}$ The scale is brief and includes 20 items answered on a seven-point Likert-type scale (Strongly Agree $=7$, Strongly Disagree $=1$ ). To control for the "acquiescence" response style (a tendency to passively and consistently endorse "agree" [or "disagree"] responses to the test questions), 10 items are positively worded (directly scored) and 10 items are negatively worded 
(reverse scored). The JSPE has received broad attention and has been translated into 25 languages to date.

Different versions of the JSPE are available: one for administration to medical students (SVersion), one for administration to physicians and other health professionals (HP-Version), and one for administration to students in any health profession fields other than medicine. These versions are similar in content with slight changes in wording to reflect students' orientation toward empathy in medical education (S-Version), or in other health profession education (HP-Version for Students), and behavioral tendencies toward empathic engagement in patient care (HP-Version for physicians and other health professionals). For example, an item in the medical students' version that reads, "Patients feel better when their physicians understand their feelings," reads as "Patients feel better when their health care providers understand their feelings" in the version for nonmedical health professional students and reads as "My patients feel better when I understand their feelings" in the HPVersion for physicians.

Evidence in support of the JSPE's construct validity,3,11,12 criterion-related validity,12,18 predictive validity,19 internal consistency reliability,11,12 and test-retest reliability 11 has been reported. Factor analysis of the JSPE in medical students 3 and physicians 11 resulted in three factors. The grand factor (prominent component) of the scale involves a construct entitled "perspective taking," which is considered an important ingredient of empathy. A related sample item from the S-version is, "Physicians" understanding of the emotional status of their patients, as well as that of their families, is one important component of the physician-patient relationship." The second component of the JSPE, "compassionate care," is considered an essential dimension of the patientphysician relationship. A related sample from the S-version item is, "Attention to patients' emotions is not important in history taking." This is a negatively worded item which is reverse scored. The third component is the "ability to stand in patients' shoes," which was a trivial factor because only two items had significant factor coefficients on this factor. A related sample item is, "Because people are different, it is difficult to see things from patients' perspectives" (a reverse scored item). A similar underlying construct of JSPE has emerged among students in dental school,20 nursing students,21 Mexican medical students, 22 Japanese 23 and Korean 24 medical students, and Italian physicians. 25 


\section{Changes in empathy}

Some anecdotal reports as well as empirical studies suggest that a drastic transformation in medical students' character occurs during their medical education. When they embark on the journey to become physicians, most students are enthusiastic, filled with idealism and a genuine intention to serve those in need of help.26,27 It is ironic, though, that despite the students' initial intentions and medical school faculty's attempts to nurture human qualities, a cynicism develops progressively during their training.26-29 For example, it has been reported that as many as three fourths of medical students become increasingly cynical about academic life and the medical profession as they progress through medical school.28 It has also been found that $61 \%$ of medical residents reported becoming cynical during their postgraduate training. 30

This cynical transformation was likened to the "battered child syndrome" and attributed to inappropriate treatment of medical students. 27 The metamorphosis has been described as "traumatic de-idealization"26 and "dehumanization." 31 It has been suggested that a "rehumanization" process is needed to retain and enhance empathy among physicians-intraining.32

Several empirical studies have shown a decline in empathy during undergraduate and graduate medical education. In a cross-sectional study, Chen and colleagues 33 reported a noticeable decline in empathy scores (measured by the JSPE) in third-year medical students as compared with their second-year counterparts. In another cross-sectional study with dental school students, Sherman and Cramer 20 noticed a significant decline in empathy (measured by the JSPE) in second-year students.

Two longitudinal studies have recently been published on the decline of empathy in medical school. Newton and colleagues 34 reported a drop in vicarious/emotional empathy (measured by the BEES) 17 during medical school. In another longitudinal study of medical students, a significant decline was observed in scores of the JSPE, which was administered at the beginning and the end of the third medical school year.35

Research also indicates that empathy continues to decline during residency training. Bellini and Shea 36 used the IRI 9 with internal medicine residents and reported a significant drop 
in scores of the "Empathic Concern" scale of the IRI, but an increase in scores of the "Personal Distress" scale of the IRI, which is an indicator of emotional empathy in the general population. Mangione and colleagues 37 noticed a downward trend in empathy scores (measured by the JSPE) as residents progressed through different years of internal medicine residency training, but the differences did not reach the conventional level of statistical significance $(\mathrm{P}<.05)$.

Although these studies generally suggest that an erosion of empathy occurs during medical education, it is important to discern exactly when and why the erosion of empathy occurs. This issue is of interest to medical educators because of its implications for timely educational intervention.

We should keep in mind that two features are important in providing an appropriate answer to the aforementioned issue. First, we need a longitudinal (as opposed to a cross-sectional) research design to follow the same group of students in different stages of medical education to examine changes in each stage. Second, we need to use a psychometrically sound measure of cognitive empathy (not affective, reactive, vicarious, or emotional empathy, which are analogous to sympathy) 3 that is both content-specific and contextrelevant to medical education and patient care.

The purpose of this study was to ascertain whether changes in empathy during medical school are systematic and progressive or disjointed without continuity. In particular, we addressed the following question: When do the most significant changes in empathy occur during medical school?

\section{Participants}

Our total study cohort included the 456 students who entered Jefferson Medical College in 2002 and 2004. This represents $100 \%$ of matriculants in these two classes. Of the total participants, $50 \%(\mathrm{n}=226)$ were women, and $74 \%(\mathrm{n}=338)$ were white, $21 \%(\mathrm{n}=95)$ were Asian American, $3 \%$ were Latino $(n=12)$, and 2\% $(n=11)$ were black.

\section{Instruments}


We used the JSPE (S-Version) in this study. In addition, to examine the reasons for any changes in empathy, we asked participants to respond to the following open-ended statement at the end of each academic year at the time the JSPE was administered: "Please describe briefly events or experiences (e.g., personal, academic, role model, etc.) in the past year that have influenced (either positively or negatively) your views on the humanistic aspect of medicine (e.g., empathy toward patient, patient-physician relationship, etc.)."

\section{Procedures}

This study, as part of the Jefferson Longitudinal Study of Medical Education (http://jdc.jefferson.edu/jlsme), approved by the IRB of Thomas Jefferson University, was conducted during a six-year period between August 2002 and March 2008. In August 2002, the JSPE was administered to 227 students during the orientation program at the beginning of their first year of medical school and then readministered in 2003 at the end of their first academic year. Subsequently, the JSPE was readministered to this cohort three more times in medical school near the end of their second, third, and fourth years in 2004 through 2006.

In August 2003, a similar procedure was started for first-year students, but data collection on that cohort was suspended because of difficulties in scheduling all the test readministrations. Once again, in August 2004, the JSPE was administered to 229 firstyear students at orientation and readministered four more times at the end of the each year through graduation in 2008 .

Participation was voluntary, and supplying personal identification information such as names or student identification numbers was optional. Therefore, not all of the students identified themselves in all test administrations. Because of this, longitudinal data were analyzed for two groups of cohorts: The "matched cohort" was the 121 students who identified themselves in all of the five test administrations, and the "unmatched cohort" (total $n=335$ ) was those who did not identify themselves in one or more of the five test administrations. 


\section{Statistical analyses}

We performed statistical analyses separately for the total study cohort, and for the matched and unmatched cohorts. We calculated descriptive statistics for comparisons of changes in empathy scores during medical school for both cohorts. In addition to descriptive statistics, we used inferential analyses (analysis of variance for repeated-measure design) to detect the statistical significance of changes in empathy scores in the matched cohort. We also used the $t$ test to test the significance of the differences in pairwise comparisons. Also, when appropriate, we calculated the effect size estimates (e.g., Cohen d) to examine whether statistically significant differences in empathy scores were also practically (clinically) significant.38

\section{Results}

Findings are presented separately for the total study sample and the matched and unmatched cohorts.

\section{Total participants}

Descriptive statistics for the empathy scores in the five test administrations for the total participants are reported in Table 2. The number of observations in different years varies from 456 on the orientation day to 356 on Match Day at the end of the fourth year because of voluntary participation, leave of absence, and dual-degree programs. For the purpose of examining the stability of the pattern of changes in different groups, we presented data separately for each entering class.

Data reported in Table 2 indicate that the mean empathy scores for entering classes in 2002 and 2004 were similar in each test administration, and results of the t test confirmed no statistically significant differences between the two sets of scores for the two classes. Therefore, we combined data for the two classes for final statistical analyses.

By comparing the empathy mean scores obtained in different years of medical school, we observed a consistent pattern of findings in each class and in the combined classes. Results consistently showed no substantial change in empathy between orientation (year 0) and the 
end of year 2. However, a considerable decline in mean empathy scores occurred in the third year of medical school. No significant trend toward improvement in empathy scores was observed in the fourth year. The decline in mean empathy score from year 0 to the end of year 3 is greater than one-half standard deviation unit (0.54), which is considered substantial and practically important. 38

\section{Comparisons of the matched and unmatched cohorts}

No significant gender difference was observed between the matched (54\% women, $\mathrm{n}=65$ ) and unmatched $(48 \%$ women, $\mathrm{n}=161)$ cohorts $\left([\mathrm{chi}]_{(1)}^{2}=1.4, \mathrm{P}=.24\right)$. The matched cohort however, was underrepresented with regard to ethnic minority (e.g., blacks, $\mathrm{n}=0$; and Latino, $\mathrm{n}=1$ in the matched group $)\left([\mathrm{chi}]_{(3)}{ }_{(3)}=8.3, \mathrm{P}<.05\right)$. Ethnic differences are unlikely to significantly influence the general findings, because no association has been found between ethnicity and scores on the Jefferson Scale of Empathy.20,39

Summary results of statistical analyses for each matriculating class and combined classes for the matched cohort are presented in Table 3. Also, corresponding statistics for the unmatched cohort are presented in the table. The 121 students in the matched cohort represent $27 \%$ of the total participants; 75 were from the entering class in 2002 and 46 from the entering class in 2004. The pattern of changes in mean empathy scores during medical school for students in both classes and for the total matched cohort combined mirrors that of the unmatched cohort. Again, the substantial decline in empathy scores occurred in year 3, yielding an effect size of 0.64 (comparing the mean scores between year 0 and year 3), which is considered practically important.38 By examining differences in empathy scores between year 0 and year 3 , we noticed a decline in empathy among $73 \%$ of students in the matched cohort $(n=88)$, indicating that erosion of empathy occurs in the majority of students but not in all of them.

As reported in Table 3, the results of analysis of variance showed that changes in empathy scores during medical school are statistically significant for the matched cohort in both classes and for the combined group. The post hoc mean comparison test confirmed that in all of the analyses reported in Table 3, the significant drop in empathy scores occurs in year 3 of medical school and remains low in year 4. Although decline in empathy in year 3 remained unchanged in year 4 for matriculants entering in 2004 (effect size $=0.05$ ), there 
is a slight but statistically insignificant increase in mean empathy score in year 4 for matriculants entering in 2002. This is also reflected in the total matched cohort. Figure 1 shows a graphical presentation of the changes in mean empathy scores for the matched and unmatched cohorts. As shown in the figure, the patterns of changes are very similar in the matched and unmatched cohorts.

\section{Gender differences}

We compared changes in empathy scores during medical school for men $(n=56)$ and women $(n=65)$ in the matched cohort. Results are depicted in Figure 2. As shown in the figure, women consistently outscored men in every year of medical school. Gender differences in all of the test administrations were statistically significant $(\mathrm{P}<.05$, by $\mathrm{t}$ test $)$. As shown in Figure 2, although the pattern of change in empathy scores for women paralleled that of men, the effect size estimates of these changes varied from a low of 0.37 (in year 2) to a high of 0.79 (in year 3 ). The effect size of the decline in empathy between year 0 and year 3 was much larger for men $(d=0.79)$ than for women $(d=0.56)$.

\section{Differences across specialties}

Changes in empathy scores were compared for 85 graduates in the matched cohort who pursued their residency training in "people-oriented" specialties (e.g., family medicine, internal medicine, pediatrics, emergency medicine, psychiatry, obstetrics-gynecology) and 36 who pursued their training in "technology-oriented" specialties (e.g., anesthesiology, pathology, radiology, surgery, orthopedic surgery, etc.). Results appear in Figure 3. As shown in the figure, those who pursued people-oriented specialties consistently scored higher in all years of medical school than did their counterparts who pursued technologyoriented specialties. However, the difference in empathy scores between the two groups became statistically significant starting from year 2 of medical school ( $\mathrm{P}<.05$, by t test). The effect size estimates of differences in empathy scores between the two groups varied from a low of 0.05 (in year 0 ) to a maximum of 0.75 (in year 3 ). The effect size of the decline in empathy from year 0 to year 3 was more than double for those who chose technology-oriented specialties $(d=1.01)$ compared with their counterparts in peopleoriented specialties $(\mathrm{d}=0.44)$. 


\section{Discussion}

The results of this study showed a significant decline in mean empathy scores in the third year of medical school. The patterns of decline were similar for men and women and for those who pursued their medical training in people-oriented and technology-oriented specialties. Consistent with previous findings, our results showed that women obtained a higher mean empathy score than men,11,12,40 and those in the people-oriented specialties outscored their counterparts in technology-oriented specialties.11,40

It is interesting to note, however, that the magnitude of the decline, measured by the effect size estimates, was larger for men compared with women, and for those who pursued technology-oriented careers compared with their counterparts in people-oriented specialties. The aforementioned findings suggest that those with lower empathy scores at the beginning of medical school (e.g., men and students interested in technology-oriented specialties) lost more empathy during medical school than others with relatively higher empathy scores at the baseline. This pattern of finding suggests that there are "at-risk" medical students who are more vulnerable to losing their sense of empathy.

What happens in the third year of medical school that hardens "the human heart by which we live" $41^{(\mathrm{p} 5)}$ and generates a noise that obscures the signal of empathic connection? The erosion of empathy in medical school can be attributed to several factors, including lack of role models, a high volume of materials to learn, time pressure, and patient and environmental factors. In addition, students' gradual overreliance on computer-based diagnostic and therapeutic technology limits their vision for the importance of human interactions in patient encounters. Changes in the market-driven health care system that have a ripple effect on medical education, combined with the belief that a controlled clinical trial is the royal road to advances in medicine, can also lead to a false idea that empathy is outside the realm of evidence-based medicine and, thus, has no importance in the education of physicians-in-training or in the practice of medicine.

In addition, modern medical education promotes physicians' emotional detachment, affective distance, and clinical neutrality $42-44$ as emphasized through a focus on the science of medicine and a benign neglect of the art of patient care. Students can easily misinterpret these lessons as an endorsement of avoiding interpersonal engagement in 
patient care. Thus, this educational approach contributes to an erosion of empathy among medical students, residents, and practicing physicians. Lack of role models,45,46 an intimidating educational environment, negative educational experiences, 47,48 partial sleep deprivation,49 and perception of "belittlement and harassment" in medical school 50 have also been described as factors contributing to the atrophy of compassion among physiciansin-training.

Although these unfavorable factors can influence a great majority of medical students, our findings that empathy did not decline for some students (a minority of 27\%) suggest that there may be certain protective factors that defuse the harmful influences. Further research is needed to investigate the protective factors that neutralize the erosion of empathy.

When analyzing the content of students' responses to the open-ended question asking about experiences that altered their views on the patient-physician relationship, we found several common themes. Students noted that the behavior of their superiors affected their own experiences: "At an affiliated hospital ... a particular attending is notorious for vulgar humor and unprofessional attitudes. So many times he made my jaw drop by the comments," and "resident and attending negative attitudes set the style in which we will act." Another student reflected that "we are always being reminded to keep a professional distance, but some doctors take it too far." Such comments reflect the negative impact of inappropriate role models. The effect of inappropriate role models, however, is not negative for all students. For example, a student wrote, "I learn [what to do] from 'good' docs and I learn what not to do from 'bad' ones!'

In addition, patient-care realities, such as overly demanding patients, lack of appreciation, malpractice issues, restrictions on caregivers' autonomy imposed by hospital guidelines, and insurance regulation, contribute to fading enthusiasm in some, but not all, medical students. For example, one student recalled "a patient who was very difficult ... was very bitter and verbally abusive to the hospital staff." Further, "It is difficult to have empathy for people who don't take care of themselves." One participant recalled "a trauma patient who gladly told us he's living off compensation money he was granted in a medical malpractice case." As another student stated, "I'm convinced it's easier to be a doctor in rural third world countries, without all the malpractice, insurance, and reimbursement 
worries of the USA." It is difficult to maintain an empathetic patient-physician relationship when "attendings have repeatedly said medicine is business."

Fear of making mistakes, a demanding curriculum, time pressure, sleep loss, and a hostile environment have all been described by some students as factors that changed their views about patient-physician relationships. As one student wrote, "I have felt overwhelmingly tired and unempathetic at times-It is the feeling where, upon walking into a patient's room, I am thinking more about getting through the encounter expeditiously than about making a connection with the patient. AND, I have always considered myself an empathetic person." One student illustrated the point facetiously: "I am too sleepy to render a sufficient answer" while another revealed that "it is hard to care $100 \%$ about some patients' stories when you are tired and have a ton of people to see." Simply put, "I think having too little time and being too busy destroys empathy." Further, "It is difficult to walk in every patient's shoes when you see so many patients in such a short time frame." Stressful training and practice environments place heavy, unrealistic demands on many students. "I think that physicians today are under so much external pressure-liability, insurance, etc. - that the patient becomes secondary." Reflecting on the nature of the training environment, one student stated, "I was constantly reminded of the hierarchy of medicine and how it was not the student's job to speak up even if in defense of patients' best interest. The bureaucratic side of medicine overshadowed the human, empathic side." When students perceive from their training experiences that the "humanistic side of medicine is too soft and a waste of time .... I worry that over time I will be 'molded by the system' into this idea."

It is interesting to note that such decline in empathy was not observed in cross-sectional studies of medical students in Japan 23 or Korea 24 (both studies used the JSPE). The inconsistent cross-cultural findings can be explained by cultural factors, curricular differences, educational experiences, role models, caregivers' autonomy, hospital guidelines, health insurance regulations, and the tradition of the patient's utmost respect for the physician.

It is important to note that our findings may be limited by the fact that our study sample was from one private medical school, and the matched cohort represented only $27 \%$ of the total cohort. These limitations, however, are somewhat mitigated by the fact that our 
medical school is similar to other large private medical schools in the United States in regard to its four-year curriculum, composition of student body, attrition rate, and career choices.

In addition, our findings that changes in mean empathy scores for the matched cohort mirrored those for the rest of the cohort suggest that the statistically significant results found in the matched cohort can be applicable to the total study participants as well. Of course, generalization of our findings can be enhanced by replicating this study in other medical schools in the United States and abroad.

\section{Conclusions}

The escalation of cynicism and atrophy of idealism has long been recognized as part of students' socialization in medical school and their adaptation to a professional role.51 This downward trend has also been observed in the ethical erosion of medical students during their clinical training.52 Hafferty $53^{(\mathrm{p} 18)}$ described this transformation as a form of "socialized amnesia" in which some medical students unwittingly acquire the unempathic quality they pledge not to adopt in the Socratic Oath. The unfortunate trend of the erosion of empathy in medical students reminds us of a gloomy remark by Novak 54 that empathy in medical education often fades away like an endangered species. To prevent extinction of this valuable human quality, we need to make profound changes in medical education by developing targeted educational programs at the undergraduate, graduate, and continuing medical education levels.

There are different approaches that can be implemented in medical schools to retain and enhance empathy. For example, the following 10 approaches have been described 55 to enhance empathy in medical education: improving interpersonal skills, analyzing audio- or video-taped encounters with patients, being exposed to role models, role-playing (aging game), shadowing a patient (patient navigator), experiencing hospitalization, studying literature and the arts, improving narrative skills, watching theatrical performances, and engaging in the Balint method of small-group discussion. It is also important to pay attention to the importance of role models, patients, and the environment in which care is given. Students should be reminded of the effect of these extrinsic factors on the quality of care they will render to their patients. Sometimes simple interventions such as not exposing 
students to disrespectful patients at the beginning of their clinical training could be helpful in retaining students' empathic orientation toward patient care.

Profound changes to enhance empathy during medical education should be considered by leaders in medical education as a mandate, not an option, if the public is to be served in the best possible manner.55 Most of us in medical education advocate empathy, but the effect of simply advocating empathy without embracing it and living with it, and without implementing targeted programs to enhance it, is analogous to singing a lovely song only in one's own mind without others ever enjoying it!55 Tangible changes in medical education outcomes can be made by actual implementation of targeted programs, not by simply advocating good ideas.

\section{Acknowledgments}

The authors would like to thank Susanne Friedman, Sherry Weitz, Edward Nicks, and Laure Deeb for their help in collection and verification of data. Dorissa Bolinski helped us in editorial polishing. We are saddened by the untimely passing of Philip Wolfson, MD, who played a significant role in the initial stages of this project.

\section{References}

1Association of American Medical Colleges. Medical School Objectives Project. Available at: (http:/www.aamc.org/meded/msop). Accessed August 2008.

2American Board of Internal Medicine. Evaluation of humanistic qualities in the internists. Ann Intern Med. 1983;99:720-724.

3Hojat M. Empathy in Patient Care: Antecedents, Development, Measurement, and Outcomes. New York, NY: Springer; 2007. 
4Kestenbaum R, Farber EA, Sroufe LA. Individual differences in empathy among preschoolers: Relation to attachment history. In: Eisenberg N, ed. Empathy and Related Emotional Responses. San Francisco, Calif: Jossey-Bass; 1989:51-64.

5Kohut H. Analysis of the Self: A Systematic Approach to the Psychoanalytic Treatment of Narcissistic Personality Disorders. New York, NY: International Universities Press; 1971.

6Basch MF. Empathic understanding: A review of the concept and some theoretical considerations. J Am Psychoanal Assoc. 1983;31:101-126.

7Eisenberg N. Empathy and Related Emotional Response. San Francisco, Calif: JosseyBass; 1989.

8Hoffman ML. The development of empathy. In: Rushton J, Sorrentino R, eds. Altruism and Helping Behavior: Social Personality Developmental Perspectives. Hillsdale, NJ: Erlbaum; 1981:41-63.

9Davis MH. Measuring individual differences in empathy: Evidence for a multidimensional approach. J Pers Soc Psychol. 1983;44:113-126.

10Hodges SD, Wegner DM. Automatic and controlled empathy. In: Ickes W, ed. Empathic Accuracy. New York, NY: Guilford; 1997:311-339.

11Hojat M, Gonnella JS, Nasca TJ, Mangione S, Vergare M, Magee M. Physician empathy: Definition, components, measurement and relationship to gender and specialty. Am J Psychiatry. 2002;159:1563-1569.

12Hojat M, Mangione S, Nasca TJ, et al. The Jefferson Scale of Physician Empathy: Development and preliminary psychometric data. Educ Psychol Meas. 2001;61:349-365.

13Nightingale SD, Yarnold PR, Greenberg MS. Sympathy, empathy, and physician resource utilization. J Gen Intern Med. 1991;6:420-423. 
14Linley PA, Joseph S. Therapy work and therapists' positive and negative well-being. J Soc Clin Psychol. 2007;26:385-403.

15Hogan R. Development of an empathy scale. J Consult Clin Psychol. 1969;33:307-316.

16Mehrabian A, Epstein NA. A measure of emotional empathy. J Pers. 1972;40:525-543.

17Mehrabian A. The Balanced Emotional Empathy Scale (BEES); 1996, unpublished document available from Albert Mehrabia, 1130 Alta Mesa Road, Moterry, CA 93940.

18Hojat M, Gonnella JS, Mangione S, et al. Empathy in medical students as related to clinical competence, gender, and academic performance. Med Educ. 2002;36:522-527.

19Hojat M, Mangione S, Nasca TJ, Gonnella JS. Empathy scores in medical school and ratings of empathic behavior 3 years later. J Soc Psychol. 2005;14:663-672.

20Sherman JJ, Cramer A. Measurement of changes in empathy during dental school. J Dent Educ. 2005;69:338-345.

21Ward J, Schaal M, Sullivan J, Bowen ME, Erdmann JB, Hojat M. Reliability and validity of the Jefferson Scale of Empathy in undergraduate nursing students. J Nurs Meas. 2009; 17:73-88.

22Alcorta-Garza A, Gonzales-Guerrero JF, Tavitas-Herrera SE, Rodrigues-Lara FJ, Hojat M. Validation of the Jefferson Scale of Physian Empathy in Mexican medical students [in Spanish]. Salud Mental. 2005;28:57-63.

23Kataoka H, Koide N, Ochi K, Hojat M, Gonnella JS. Measurement of empathy among Japanese medical students: Psychometrics and score differences by gender and level of medical education. Acad Med. 2009;84:1192-1197.

24Roh MS, Hahm BJ, Lee DH, Suh DH. Psychometric properties of the Jefferson Scale of Physician Empathy among Korean medical students. Teach Learn Med. (in press). 
25Di Lillo M, Cicchetti A, Lo Scalzo A, Taroni F, Hojat M. The Jefferson Scale of Physician Empathy: Preliminary psychometrics and group comparisons in Italian physicians. Acad Med. 2009;84:1198-1202.

26Kay J. Traumatic deidealization and future of medicine. JAMA. 1990;263:572-573.

27Silver HK, Glicken AD. Medical student abuse: Incidence, severity, and significance. JAMA. 1990;263:527-532.

28Sheehan KH, Sheehan DV, White K, Leibowitz A, Baldwin DC Jr. A pilot study of medical student 'abuse': Student perceptions of mistreatment and misconduct in medical school. JAMA. 1990;263:533-537.

29Wolf TM, Balson PM, Faucett JM, Randall HM. A retrospective study of attitude change during medical education. Med Educ. 1989;23:19-23.

30Collier VU, Macue JD, Markus A, Smith L. Stress in medical residency: Status quo after a decade or reform? Ann Intern Med. 2002;136:384-390.

31Edwards MT, Zimet CN. Problems and concerns among medical students. J Med Educ. 1976;51:619-625.

32Kumagai AK. A conceptual framework for the use of illness narrative in medical education. Acad Med. 2008;83:653-658.

33Chen D, Lew R, Hershman W, Orlander J. A cross-sectional measurement of medical student empathy. J Gen Intern Med. 2007;22:1434-1438.

34Newton BW, Barber L, Clardy J, Cleveland E. Is there hardening of the heart during medical school? Acad Med. 2008;83:244-249.

35Hojat M, Mangione S, Nasca TJ, et al. An empirical study of decline in empathy in medical school. Med Educ. 2004;38:934-941. 
36Bellini LM, Shea JA. Mood change and empathy decline persist during three years of internal medicine training. Acad Med. 2005;80:164-167.

37Mangione S, Kane CK, Caruso JW, Gonnella JS, Nasca TJ, Hojat M. Assessment of empathy in different years of internal medicine training. Med Teach. 2002;24:370-373.

38Hojat M, Xu G. A visitor's guide to effect size: Statistical versus practical (clinical) importance of research findings. Adv Health Sci Educ Theory Pract. 2004;9:241-249.

39Ward J, Scaal M, Sullivan J, Bowen ME, Erdmann JB, Hojat M. A measurement of empathy in nursing students. J Nurs Meas. 2009;17:73-88.

40Hojat M, Gonnella JS, Nasca TJ, Mangione S, Veloski JJ, Magee M. The Jefferson Scale of Physician Empathy: Further psychometric data and differences by gender and specialty at item level. Acad Med. 2002;77(suppl):S58-S60.

41Osler W. Aequanimitas: With Other addresses to Medical Students, Nurses, and Practitioners of Medicine. Birmingham, Ala: Classics of Medical Library; 1987 (originally published in 1904).

42Halpern J. From Detached Concern to Empathy: Humanizing Medical Practice. New York, NY: Oxford University Press; 2001.

43Farber NJ, Novack DH, O'Brien MK. Love, boundaries, and patient-physician relationships. Arch Intern Med. 1997;157:2291-2294.

44Coulehan J, Williams PC. Vanishing virtue: The impact of medical education. Acad Med. 2001;76:598-605.

45Skeff KM, Mutha S. Role models: Guiding the future of medicine. N Engl J Med. 1998;339:2017. 
46Wright SM, Kern DE, Kolodner K, Howard DM, Brancati FL. Attributes of excellent attending physician role models. N Engl J Med. 1998;339:1986-1993.

47Kramer D, Ber R, Moore M. Impact of workshop on students' and physicians' rejecting behavior in patient interviews. J Med Educ. 1987;62:904-910.

48Diseker RA, Michielutte R. An analysis of empathy in medical students before and following clinical experiences. J Med Educ. 1981;56:1004-1010.

49Killgore WD, Kahn-Greene ET, Lippizzi EL, Newman RA, Kamimori GH, Balkin TJ. Sleep deprivation reduces perceived emotional intelligence and constructive thinking skills. Sleep Med. 2008;9:517-526.

50Frank E, Carrera JS, Stratton T, Bickel J, Nora LM. Experiences of belittlement and harassment and their correlates among medical students in the United States: Longitudinal survey. BMJ. 2006;333:682-688.

51Becker HS, Geer B, Hughes EC, Strauss AL. Boys in White: Student Culture in Medical School. Chicago, Ill: The University of Chicago Press; 1961.

52Feudtner C, Christakis DA, Christakis NA. Do clinical clerks suffer ethical erosion? Students' perceptions of their ethical environment and personal development. Acad Med. 1994;68:670-679.

53Hafferty WF. Into the Valley: Death and the Socialization of Medical Students. New Haven, Conn: Yale University Pres; 1991.

54Novak DH. Therapeutic aspects of the clinical encounter. J Gen Intern Med. $1987 ; 2: 346-355$.

55Hojat M. Ten approaches for enhancing empathy in health and human services culture. J Health Hum Serv Adm. 2009;31:412-450. 
